\title{
Avaliação do desempenho de uma manufatura de equipamentos eletrônicos segundo critérios de competição
}

\author{
Miguel Afonso Seluitto \\ PPGEPS Universidade do Vale do Rio dos Sinos - Unisinos \\ Cláudio Walter \\ PPGEP Universidade Federal do Rio Grande do Sul - UFRGS
}

\begin{abstract}
Resumo
Este artigo apresenta um caso em que foi avaliado o desempenho de uma manufatura de equipamentos eletrônicos segundo critérios de competição. $\mathrm{O}$ objetivo de pesquisa é propor e testar um método para esta avaliação, que inclui um grupo focado conduzido pelo pesquisador junto a estrategistas da empresa. A estratégia existente foi traduzida em uma estrutura em árvore ponderada pelo método AHP. A estrutura deu origem a um questionário, que avaliou o desempenho geral e o desempenho parcial dos diversos critérios de competição que compõem a estratégia, segundo os respondentes. Comparando-se a importância relativa de cada critério com o seu desempenho, estabeleceram-se prioridades estratégicas para a manufatura. Como continuidade de pesquisas, sugere-se o uso do método para a reformulação das atuais estratégias e para a identificação de indicadores de medição direta, em complementação à medição indireta obtida pelo uso do questionário.
\end{abstract}

Palavras-chave

Avaliação de desempenho em manufatura; critérios de competição em manufatura; estratégia em manufatura; modelagem de estratégia em manufatura.

\section{Performance assessment of a manufacture firm of electronic equipment in terms of competitive priorities}

\begin{abstract}
This paper reports the performance assessment of a manufacturer firm of electronic equipment in terms of his competitive priorities. The research goal is to propose and test a method for this assessment, beginning with a focus group led by the researcher with the strategic management team of the firm, in which the manufacturing strategy in use was reported as a tree-like structure, weighted with the aid of the AHP. The structure gave rise to a questionnaire, in which the team assessed the actual performance of the strategy as a hole and issue by issue. By comparing the assessed performance with the relative importance of the strategic issues, one can prioritize strategy formulations for the manufacture. For the sake of continuity, one suggests the use of the method for modifications in the existing strategy and for pointing out direct-measured indicators, in addiction to the indirect assessing method now developed.
\end{abstract}

Key words

Performance measurement in manufacturing; competitive priorities in manufacturing; manufacturing strategy; modelling in manufacturing strategy. 


\section{INTRODUC̣ÃO}

A manufatura em geral, e a manufatura eletrônica em particular, tem sido influenciada pela expansão da competição global, por mudanças nos mercados tecnológicos e pelo aumento na complexidade e na incerteza do ambiente competitivo. Além do custo e da confiabilidade dos produtos, também a entrega e a capacidade de inovação passaram a influenciar a competição, o que têm modificado as estratégias de manufatura. Ao enfoque industrial exclusivo de eficiência e automação rígida têm sido agregados enfoques pós-industriais de rápida resposta a clientes (WIENDAHL, 1995; TRACEY, VONDEREMBSE \& LIM, 1999).

Segundo Skinner (1986, apud TRACEY, VONDEREMBSE e LIM, 1999), no ambiente pós-industrial, as fontes de competitividade em manufatura passaram a exigir altos níveis de qualidade, confiabilidade e inovatividade em produtos e flexibilidade nos sistemas produtivos, abrindo mão da competição baseada exclusivamente na produção em massa e na redução do custo unitário de produtos.

Conclui-se que o atual processo estratégico exige novos objetivos para a manufatura.

Uma parte relevante do processo estratégico é a medição e o controle dos resultados gerados pela aplicação de estratégias. Se esta medição for incompatível com os objetivos estratégicos, estes podem não ser atingidos. Para Müller (2003), a competitividade de uma organização depende do alinhamento entre esforços e estratégia: um sistema de avaliação de desempenho deve ser o elo de realimentação entre os objetivos da estratégia e os esforços para atingi-los.

Segundo Martins (1999), os sistemas de medição mais encontrados até 1990 se preocupavam mais com resultados financeiros do que com outras dimensões de desempenho. Metas exclusivamente financeiras, tais como o lucro líquido e a taxa de retorno de investimentos, assumiam o papel de referencial de desempenho de empresas. Segundo Bourne et al. (2000) e Kennerly e Neely (2003), tais medições acarretam, entre outros problemas: (i) falta de informação sobre o desempenho futuro; (ii) enfoque em otimizações de curto prazo e locais; (iii) perda de alinhamento com estratégias mais elaboradas de produção; e (iv) pouca informação para decisões em ambientes turbulentos. Segundo Kaplan e Norton (1997), medições exclusivamente financeiras não são mais eficazes no controle estratégico de uma organização, sendo necessárias medições que considerem valores intangíveis, tais como o aprendizado e o crescimento. Segundo Suwignjo, Bititci e Carrie (2000), pesquisas recentes comprovaram que medições financeiras não são capazes de medir e integrar todos os fatores críticos exigidos para o sucesso de uma operação. Barker (1996, apud MIRANDA e SILVA, 2002) conclui que medidas puramente financeiras são suficientes apenas se a concorrência não é acirrada, as mudanças são lentas ou há pouca introdução de novos produtos.

Este cenário sugere inovações na medição de desempenho em operações.

Propostas para medição de desempenho em operações são recorrentes na literatura. Neely, Gregory e Platts (1995), Bourne et al. (2000), Hudson, Smart e Bourne (2001), Kennerly e Neely (2002; 2003) e Evans (2004) são alguns dos autores que apresentaram revisões sobre o tema. Miranda e Silva (2002) revisaram vinte e uma propostas apresentadas após 1990. Evans (2004) afirma que as estruturas de medição de desempenho mais influentes já apresentadas na literatura são o Balanced Scorecard (BSC) e a estrutura do prêmio Malcolm Baldridge para a excelência.

\section{ma parte relevante do processo estratégico é a medição e o controle dos resultados gerados pela aplicação de estratégias.}

Entende-se que as quatro perspectivas do BSC e os sete critérios ponderados do prêmio Malcolm Baldridge permitem enfocar objetivos de competição no planejamento das medições. Estruturas formais como estas, no entanto, reduzem a flexibilidade das medições, podendo, sob certas circunstâncias, descolá-las da estratégia, se esta mudar frequientemente.

O objetivo deste artigo é propor e testar uma metodologia para a avaliação do desempenho de uma manufatura, obtendo uma estrutura de avaliação que contenha e pondere critérios de competição reconhecidos e cuja modificação seja razoavelmente simples. A metodologia será testada e refinada em uma manufatura de equipamentos eletrônicos. O artigo está organizado em (i) considerações sobre estratégia e competitividade em manufatura; (ii) considerações sobre estruturas de medição de desempenho; (iii) apresentação e aplicação da metodologia; e (iv) discussão e continuidade de pesquisa.

\section{COMPETITIVIDADE E ESTRATÉGIA EM MANUFATURA}

Uma operação de manufatura deve satisfazer seus consumidores e superar seus concorrentes, formulando e 
perseguindo objetivos de competitividade. Hill (1995) sugere uma classificação de objetivos em (i) ganhadores de pedidos, que garantem o fechamento de negócios; e (ii) qualificadores, cuja presença não garante, mas a ausência impede o negócio.

Autores estruturaram objetivos para a competitividade na manufatura. Slack (1993) aponta cinco objetivos: (i) qualidade do produto; (ii) velocidade nas entregas; (iii) confiabilidade nas entregas; (iv) flexibilidade nas entregas; e (v) custo dos produtos. Contador (1996) também aponta cinco objetivos, chamando-os de campos de competição: (i) preço; (ii) produto; (iii) prazo até o uso; (iv) assistência e serviços; e (v) imagem associada ao produto. Davis, Aquilano e Chase (2001) apontam cinco prioridades competitivas: (i) baixo custo; (ii) alta qualidade; (iii) rapidez; (iv) ampla variedade; e (v) serviços associados ao produto. Finalmente, Paiva, Carvalho e Fensterseifer (2004) falam em: (i) custo; (ii) qualidade; (iii) flexibilidade; (iv) desempenho de entrega; e (v) inovatividade.

A competitividade resulta da execução de uma estratégia. Uma estratégia empresarial assume três níveis: corporativa, de negócios e funcional. A estratégia corporativa relaciona-se com o ambiente em que o grupo empresarial atua, reconhecendo forças e fraquezas próprias e peculiaridades do ambiente de negócios. Da interação destes fatores surge a competência distintiva que cada unidade de negócio ostenta e que será explorada na estratégia de negócios (PAIVA, CARVALHO \& FENSTERSEIFER, 2004; WHEELWRIGHT, 1984).

Estratégias de manufatura residem no nível funcional. Para Wheelwrigth (1984), estratégias de manufatura são seqüências de decisões tomadas ao longo do tempo em várias áreas de decisão e que criarão vantagens competi- tivas na indústria. Contador (1996) chama estas vantagens de armas de competição. Wheelwrigth (1984) aponta as categorias de decisões: (i) capacidade de produção; (ii) localização, tipologia, volume e ciclo de vida de instalações; (iii) equipamentos, lay-outs e tecnologia de operação; (iv) integração vertical e opções do tipo comprar ou fazer; (v) recursos humanos; (vi) requisitos de qualidade a serem atendidos; (vii) escopo de produção e de novos produtos; (viii) sistemas de gerenciamento que serão requeridos; e (ix) relações entre as estratégias funcionais.

Paiva, Carvalho e Fensterseifer (2004) consideram a estratégia de manufatura em conjunto com estratégias de pesquisa e desenvolvimento e de marketing e vendas, tratando-as como uma meso-estratégia de gestão da demanda, conforme a Figura 1. Os autores entendem as relações entre a estratégia de negócios e as estratégias funcionais segundo relações hierárquicas. Uma estratégia de hierarquia superior se desdobra em estratégias de hierarquia inferior, que a recompõem e sintetizam. Se bem que a figura aponte o sentido alto-baixo, não se deve ignorar o sentido inverso: competências identificadas nas operações influenciariam a estratégia superior. Interações verticais também são observadas: objetivos de uma estratégia funcional podem depender de competências residentes em outras estratégias funcionais.

A estratégia de manufatura se subordina à estratégia de negócios através da competitividade que a manufatura possa agregar ao negócio. Para Skinner (1969), este é o elo que conecta a estratégia de manufatura à estratégia de negócios. A manufatura coordena e gerencia os esforços de produção de produtos e serviços, ao longo de uma cadeia geradora de valor. A cadeia de valor de produção

Figura 1: Relacionamento entre estratégias.

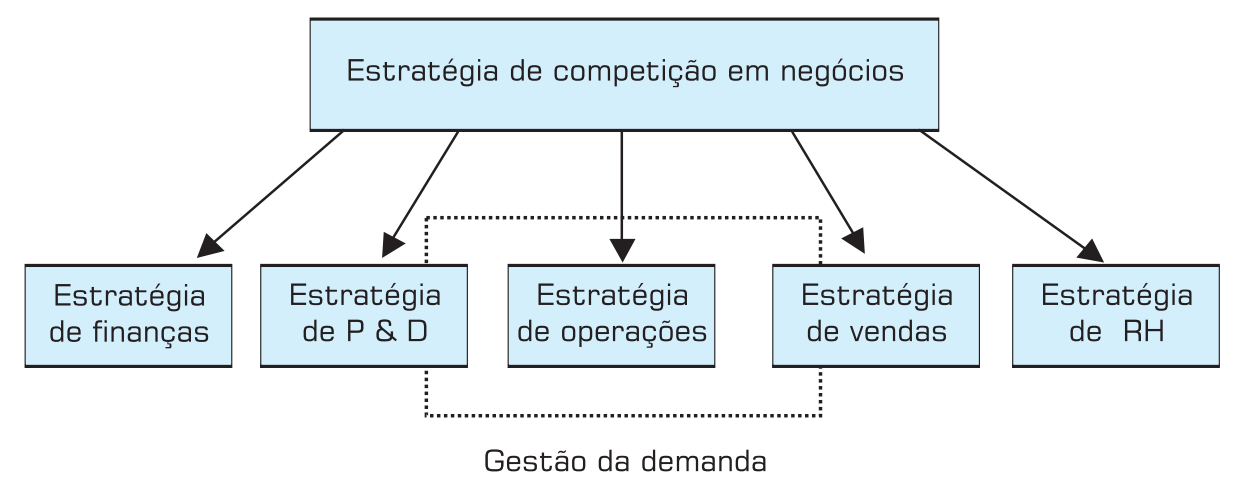

Fontes: Adaptado de Paiva; Carvalho e Fensterseifer (2004) e de Wheelwright (1984) 
se inicia no projeto do produto e do processo de fabricação, passa por fornecimentos, fabricação, armazenagem e distribuição, chegando aos serviços associados. A estratégia de manufatura inclui decisões interligadas e mutuamente coerentes que devem cobrir toda a gama de atividades incluída na cadeia (SKINNER,1996).

Parafraseando Porter (1998), Paiva, Carvalho e Fensterseifer (2004) argumentam que, em operações, três classes de estratégias são identificáveis: liderança pura em custo, diferenciação pura de produto e foco simultâneo em custo e em diferenciação de produto. A estratégia de liderança pura em custo se sustenta principalmente na economia de escala, obtida com investimentos de capital e padronização de produto. A estratégia de diferenciação pura se sustenta no aumento da qualidade e na redução do tempo até o uso de produtos, obtidos principalmente por investimentos em mercadologia, pesquisa, desenvolvimento, inteligência competitiva e criatividade. A estratégia de foco se sustenta na ruptura do compromisso (trade-off) entre custo e diferenciação, classicamente determinado pela economia de escala. A ruptura surge com a introdução da flexibilidade na manufatura, principalmente através dos chamados sistemas flexíveis de manufatura e da manufatura apoiada por computador (PAIVA, CARVALHO e FENSTERSEIFER, 2004).

\section{Competitividade interna e na indústria}

Para Hayes e Wheelwrigth (1984), a competitividade em operações resulta da aplicação de duas classes de estratégias: (i) a estratégia estrutural, que define aspectos de longo tempo de maturação, tais como a localização industrial e a tecnologia de produção; e (ii) a estratégia infra-estrutural, que diz respeito a fatores de menor prazo de maturação, tais como o tipo e o tamanho da força de trabalho, o nível de qualidade e a flexibilidade da produção.

Segundo Ferraz, Kupfer e Haguenauer (1996), estudos anteriores não conduziram a uma definição de competitividade e, por conseqüência, a uma metodologia para a sua medição. Para os autores, as raízes da competitividade têm sido localizadas ora em fatores internos às empresas, tais como a tecnologia, a qualidade dos produtos ou a adoção de técnicas específicas, como a produção enxuta, ora em fatores ambientais, tais como baixos custos de produção em regiões, baixas taxas de inflação ou taxas favoráveis de câmbio.

Os autores propõem que a competitividade seja a capacidade que a empresa tem de formular e implementar estratégias concorrenciais que ampliem e mantenham uma posição vantajosa na indústria, dependente de fatores, muitos deles subjetivos e não-mensuráveis. A competitividade seria uma variável multifacetada que incluiria duas visões: uma que sintetiza variáveis que já se manifestaram, como o preço e a capacidade de atendimento, e outra que sintetiza variáveis apriorísticas, como a capacitação que a empresa construiu. O desempenho atual na competição seria uma conseqüência do esforço da empresa em acumular capacitação e refletiria o resultado das estratégias competitivas adotadas em função de sua percepção, tanto do embate concorrencial quanto do meio ambiente. Ao invés de ser um atributo de um produto ou de uma empresa, a competitividade seria uma característica relacionada com o padrão de concorrência vigente na indústria, ou seja, o conjunto dinâmico de fatores críticos de sucesso, composto pelos fatores propriamente ditos e por suas relações de interferências mútuas.

\section{A estratégia de manufatura se subordina à estratégia de negócios avés da competitividade que a nufatura possa agregar ao negócio.}

Porter (1998) lança luz à discussão ao propor um modelo para a criação da vantagem competitiva, considerando tanto fatores externos como internos à organização. O modelo de Porter não se fixa nos fatores já citados, que seriam as fontes da vantagem competitiva, mas nas suas conseqüências, representadas por forças, tais como a capacidade de clientes, fornecedores, entrantes e substitutos de influenciar o resultado do processo concorrencial.

Carvalho e Laurindo (2003) afirmam que o sucesso de uma estratégia competitiva se vale, além dos fatores internos de capacitação da empresa, do conhecimento das regras de competição e do ambiente em que a competição se dá. Tais regras nem sempre são claras e, quando o são, podem mudar, requerendo respostas ágeis dos decisores. Segundo os autores, é preciso que se acompanhem as mudanças ambientais, mantendo canais de comunicação permanentes com as novas tecnologias e com os clientes e manter-se informado sobre os movimentos dos concorrentes. A elaboração e a execução de uma estratégia competitiva dependeriam, portanto, de se mapear permanentemente o cenário, a fim de aproveitar as oportunidades e neutralizar as ameaças do ambiente competitivo. 
Peteraf (1993) apresenta outro enfoque. Segundo a autora, a presença dos fatores produtivos varia em uma indústria, apresentando diferentes capacidades de influenciar a competitividade. Os detentores dos fatores competitivos de mais alta capacidade e de acesso limitado competem em condições mais favoráveis do que os detentores de recursos marginais e facilmente alcançáveis. Recursos competitivos de acesso limitado são: (i) fixos, se não podem ser multiplicados; (ii) quase-fixos, se podem ser multiplicados, mas em velocidade menor do que o requisito; e (iii) escassos, se forem menores que o requisito. Para a autora, o ponto-chave da competitividade estaria em manter fixos apenas os recursos de importância superior. As empresas permaneceriam competitivas se estes recursos não pudessem ser livremente expandidos, contratados ou imitados pelos concorrentes.

\section{ESTRUTURAS DE MEDIC̣ÃO DE DESEMPENHO}

Dois interesses distintos são considerados ao medir-se o desempenho de uma organização. O primeiro interesse diz respeito ao público externo, tal como o mercado acionário, o poder público e sindicatos, e é atendido pela contabilidade financeira sob a forma de balanços patrimoniais e sociais. O segundo interesse diz respeito ao público interno e deve ser atendido por sistemas estruturados de medição de desempenho.

Para Miranda e Silva (2002), a principal função da medição de desempenho é verificar se e em que grau a missão da organização está sendo cumprida. Segundo os autores, ao estruturar-se um sistema de medição de desempenho, três perguntas devem ser respondidas: (i) por que medir, exigindo clareza acerca da missão; (ii) o que medir, exigindo que os principais campos de força vigentes na organização sejam explicitados e entendidos; e (iii) como medir, exigindo um processo de relacionamento entre as grandezas que operam os campos de força, geralmente latentes, e variáveis manifestas que possam, com suficiente confiabilidade, capturar e descrever o seu comportamento. O sistema de medição de desempenho deve fornecer elemen-

A autora aponta quatro condições para o surgimento da vantagem competitiva: (i) a diversidade de recursos competitivos gera um desequilíbrio favorável; (ii) a imposição de limites do tipo ex-post, ou seja, criados a posteriori pela empresa, tais como dificuldades para substituição ou imitação, torna intransponível o desequilíbrio gerado pela diversidade; (iii) a mobilidade imperfeita dos fatores competitivos impede que estes sejam compartilhados entre concorrentes; e (iv) a imposição de limites do tipo ex-ante, ou seja, criados a priori pela empresa, tais como alta produtividade, previne elevações de custos internos e mantém a vantagem conquistada. Em resumo, a estratégia da empresa deve aproveitar-se da diversidade natural de recursos existente na indústria e criar uma situação vantajosa. A vantagem será preservada por limites impostos para a sua obtenção por concorrentes, que teriam acesso apenas a versões inferiores do recurso, e será mantida por ações internas redutoras de custo. A autora reconhece que estes fatores não são mutuamente independentes, caracterizando a heterogeneidade no cenário como o fator que cria as condições vantajosas, cabendo aos demais fatores a determinação de sua intensidade. tos para a tomada de decisão, em um processo que exige dados coletados, processados, agregados e apresentados com uma conveniente freqüência e suficiente precisão.

Para Bourne et al. (2000), a medição de desempenho tem duas funções: (i) medir o sucesso de uma estratégia; e (ii) verificar a validade dos pressupostos assumidos ao se formular a estratégia. Para Hronec (1993), as medições de desempenho constituem os sinais vitais da organização, comunicando a estratégia para baixo e os resultados para cima. Os indicadores da medição devem ser derivados da missão e da visão de futuro da organização e devem englobar a totalidade do entendimento acerca dos conceitos e objetivos e suas relações subjacentes de causa e efeito. Kasul e Motwani (1995) consideram que, antes de se propor um sistema de medição de desempenho, os fatores críticos para o sucesso de uma operação devem ser identificados e interpretados. Ao invés de se adotarem indicadores dissociados uns dos outros, cada um medindo o desempenho de um aspecto isolado, devese integrar os indicadores segundo uma regra vinculada à estratégia da organização.

Bourne et al. (2000) dividem o processo de implantação da medição de desempenho em especificação, im- 
plementação e uso das medições. Segundo os autores, a fase de especificação das medições é um processo cognitivo em que as visões de estrategistas são transformadas em objetivos de negócios e em medições capazes de mensurá-los. A fase de implementação é um processo mecanístico gerenciável por metodologias de controle de projeto e baseada em tecnologia de informação. Por fim, a fase de uso consiste na atualização e manutenção das medições, em um processo permanente de evolução e aprendizado.

Kennerly e Neely (2003) observam que as empresas têm atribuído menos atenção ao gerenciamento da última fase. Segundo os autores, há pouca evidência de que, havendo mudanças no ambiente de negócios, o sistema de medição continue refletindo as necessidades organizacionais. Para Bourne et al. (2000), o sistema de medição de desempenho deve prever um procedimento de inserção, remoção e revisão de medições, executável sempre que sejam detectadas modificações no ambiente de competição ou na estratégia de operação. Este artigo tratará mais da primeira e da terceira fase apontadas.

Müller (2003) separa os sistemas de avaliação de desempenho mais conhecidos em quatro classes: (i) modelos com ênfase financeira, tais como o modelo EVA; (ii) modelos clássicos, tais como os propostos pela TQM; (iii) modelos estruturados, tais como os modelos propostos pelo BSC e pelo prêmio Malcolm Baldridge; e (iv) modelos específicos, tais como o modelo Quantum, de Hronec (1993).

Propõe-se outra classificação, conforme a estrutura de medição: (i) nos sistemas levemente estruturados, as medições se limitariam a mensurar os resultados de planos de ação que, mesmo que cumpram objetivos estruturados, não guardam relações lógicas entre si; (ii) nos sistemas medianamente estruturados, as medições seriam divididas em temas afins fixos e gerariam resultados intermediários com ponderação variável; e (iii) nos sistemas fortemente estruturados, as medições seriam divididas em temas afins fixos e gerariam resultados intermediários com ponderação fixa.

A primeira classe tem flexibilidade e responde rapidamente a variações nos objetivos estratégicos, porém, por não possuir estrutura formal, não se presta para comparações e não representa estratégias complexas. O sistema informa os valores requisitados, cabendo ao decisor a interpretação. São exemplos as medições propostas pelo TQM e os sistemas de informação gerencial baseados em relatórios. A segunda classe mensura temas que mantém entre si uma relação lógica seqüencial (não necessariamente de causalidade) ou em forma de árvore ponderável. Como exemplos, tem-se o modelo Quantum (HRONEC, 1993) e o BSC. A terceira classe incorpora sistemas de medição cujos temas estratégicos, além de terem relações lógicas entre si, são ponderados e invariáveis no tempo, gerando séries históricas comparáveis, tais como o prêmio Malcolm Baldridge, que permite comparar o desempenho de empresas diferentes dentro e fora da indústria. Sendo uma solução de compromisso, tais modelos endereçam situações intermediárias que descrevem aproximadamente qualquer empresa-alvo. No entanto, se o cenário varia mais rapidamente do que os temas e pesos, a medição descola da estratégia.

Os sistemas levemente estruturados são fáceis de implantar e de flexibilizar, mas têm baixa capacidade de comparação. Por exemplo, a eficiência de cimenteiras não é comparável à eficiência de hospitais. Sistemas medianamente estruturados não são de implantação tão fácil, porque exigem a explicitação da estratégia em termos de relações de causa-efeito e alguma ponderação. Seus resultados, por serem agregados, têm alguma comparabilidade: a perspectiva de aprendizado de cimenteiras e de hospitais, dentro de circunstâncias, pode ser comparada. Por fim, os sistemas fortemente estruturados são de fácil implantação, por já estarem prontos, de grande comparabilidade, por manterem a ponderação, mas de baixa flexibilidade, pois não admitem modificações.

Estas características são resumidas no Quadro 1.

O Quadro 1 sugere uma lacuna: nenhuma das classes tem ao mesmo tempo grande comparabilidade e grande flexibilidade. Uma classe de medição flexivelmente estruturada seria tão flexível quanto a medição levemente estruturada e ofereceria séries históricas comparáveis, eventualmente abrindo mão da facilidade de implantação. A proposta que segue tem a intenção de explorar esta lacuna.

Quadro 1: Classes comparadas de sistemas de medição.

\begin{tabular}{|c|c|c|c|}
\hline MEDIÇÃO & FACILIDADE & FLEXIBILIDADE & COMPARABILIDADE \\
\hline levemente estruturada & grande & grande & baixa \\
\hline medianamente estruturada & média & média & média \\
\hline fortemente estruturada & grande & baixa & grande \\
\hline
\end{tabular}

Fonte: elaborado pelos autores 


\section{ESTUDO DE CASO: AVALIACূÃO DO DESEMPENHO DE UMA MANUFATURA DE EQUIPAMENTOS ELETRÔNICOS}

Chega-se ao objetivo central do artigo: a avaliação de desempenho de uma manufatura que opera em ambiente competitivo. Entende-se que o desempenho em manufatura seja uma grandeza multivariável dinâmica e que seja difícil obter uma modelagem permanente, comparável e transportável, adequada a todas as indústrias. Julga-se necessária uma metodologia flexivelmente estruturada, replicável no tempo e na indústria, que possa gerar e ponderar um conjunto de variáveis de medição. A metodologia deverá usar uma técnica qualitativa para a estruturação e uma técnica quantitativa para a ponderação de medições que expliquem e integrem os objetivos de competição. A partir de agora utiliza-se o termo avaliação, o que pressupõe o uso de julgamento de decisores, em oposição ao termo medição, que pressupõe o uso de grandezas físicas.

postos por hardware e software especificamente desenvolvidos. Controladores programáveis $(\mathrm{CP})$ são bens de capital usados em indústrias de alto valor agregado. Há dois tipos de clientes: as empresas de engenharia, que especificam, compram e usam CPs em projetos industriais; e os contratantes dos projetos, que acompanharão o desempenho, farão a manutenção e relatarão os problemas observados nos CPs. A empresa possui uma planta localizada em campus universitário, em região industrializada, e é abastecida por uma cadeia de suprimentos que envolve operações internacionais. A empresa é nacional, originada em ambiente universitário, e concorre com fabricantes transnacionais. O mercado é principalmente o de instalações industriais (reforma, modernização e automação de máquinas autônomas, integradas e de processos industriais). Desde a sua fundação, a empresa sempre cresceu, tanto no mercado nacional, em que ocupa uma das principais posições, quanto no mercado internacional, entrando em novas regiões. Opera no exterior com escritórios próprios e representantes, incorporando em seus fornecimentos equipamentos periféricos fabricados por parceiros, inclusive do exterior.

A estratégia da manufatura é definida: (i) o projeto do produto é feito por técnicos locais empregados da empresa, em associação com universidades e centros de pesquisa afins e considera particularidades

Propõe-se uma metodologia de pesquisa e de trabalho:

- Etapa qualitativa: escolha de uma organização competitiva em uma indústria e convite a estrategistas com conhecimento e trajetória de sucesso para participar de um grupo focado. Nesta etapa investigar-se-ão aspectos referentes à competitividade, cabendo ao pesquisador obter uma estrutura em forma de árvore, segundo os decisores;

- Transformação da estrutura em questionário e aplicação aos decisores;

- Análise de confiabilidade pelo alpha de Crombach;

- Aplicação do método AHP para ponderar os níveis da estrutura em forma de árvore;

- Obtenção de um valor numérico que expresse o desempenho estratégico, segundo os decisores; e

- Discussão do caso e refinamento do método.

Escolheu-se uma manufatura que produz equipamentos eletrônicos para uso em automação industrial. Justifica-se a escolha porque a competitividade nesta indústria tem se acentuado e o cenário de competição é global: a empresa vende e entrega equipamentos no Brasil e no exterior, concorrendo e cooperando com atores globais.

A empresa produz controladores programáveis, com- requeridas por clientes; (ii) o fornecimento de materiais é feito por importadores em associações com redes locais de suprimento; (iii) a venda é feita pela empresa e por representantes autorizados; (iv) a fabricação é feita sob encomenda e é confiada a empresas locais; (v) a montagem, teste e embalagem são feitos na empresa; (vi) a distribuição é feita pela empresa e por distribuidores autorizados; (vii) os serviços associados ao produto são executados pela empresa e por assistentes técnicos autorizados; e (viii) boa parte da equipe é considerada como trabalhadores do conhecimento.

A estruturação dos objetivos de competitividade requer a modelagem de fatores intangíveis, originados das crenças e das diferentes percepções dos decisores. Para a construção da estrutura de competitividade constituiu-se um grupo focado.

A estrutura de competitividade originou um questionário, pelo qual o grupo avaliou a situação da empresa perante os fatores em estudo. Testou-se a confiabilidade das respostas pelo alpha de Crombach, cuja teoria é encontrada em Hair et al. (1998). O teste aponta que perguntas suscitaram diferentes interpretações nos respondentes, sugerindo modificações para outras aplicações. 
A seguir os especialistas julgaram as importâncias relativas dos fatores críticos de primeiro e de segundo nível da estrutura, com o apoio do AHP (Analytic Hierarchy Process), chegando a uma ponderação dos fatores. O AHP é um dos primeiros métodos propostos e possivelmente seja o mais usado e mais conhecido no campo da decisão multicriterial (GOMES, ARAYA e CARIGNANO, 2004). Os autores recomendam seu uso quando há suficiente independência e capacidade de discriminação entre as alternativas de decisão. O método é apresentado em Saaty (1991) e requer o cálculo dos autovetores de máximo valor e das $C R$ s, as razões de consistência dos julgamentos. Para tanto, foi usada uma planilha eletrônica, cujos resultados são compatíveis com resultados documentados do software Expert Choice.

Ao fim, com as respostas aos questionários e as ponderações obtidas pelos julgamentos, chegou-se a um valor numérico que corresponde à percepção dos decisores sobre a situação de competitividade da empresa. Comparando-se os resultados de desempenho dos fatores críticos com o seu potencial de influência na competitividade, surgiram as lacunas de desempenho.

\section{Resultados}

A empresa indicou quatro decisores com formações compatíveis com a pesquisa, experiências e trajetórias de sucesso na indústria eletrônica. Como fio condutor da investigação, elaboraram-se questões, segundo Ribeiro e Newmann (2003): (i) questão inicial: o que o grupo entende por competitividade? (ii) questão de transição: o grupo reconhece que a empresa opera em um cenário competitivo? (iii) questões centrais: como o grupo descreve e interpreta o cenário competitivo em que a empresa opera? (iv) questão de resumo: quais os fatores ligados à manufatura que o grupo reconhece como capazes de gerar sucesso no cenário competitivo em que a empresa opera?; e (v) questão final: como cada um dos fatores acima é constituído?

A primeira questão investigou o conceito de competitividade. Algumas expressões foram observadas: concorrentes; disputa; superação de oponentes; conhecimento de forças e fraquezas próprias e de adversários; estratégia ligada aos concorrentes; posicionamentos em relação a concorrentes; definir objetivos e preferências, entender os objetivos e preferências dos adversários; errar menos do que os adversários; estabelecer diversos cursos de ação; escolher entre diversos cursos de ação; cenários probabilísticos de futuro; onde estou, onde quero chegar, que forças preciso para chegar. Os participantes manifestaram a existência de animosidade e rivalidade na indústria.

A segunda questão investigou como o grupo reconhe- ce o cenário da operação. Segundo o grupo, todos os fatores apontados na primeira resposta estão presentes. O grupo tem clara visão sistêmica, reconhece os vértices, as arestas, a fronteira e a superfície do sistema de manufatura e reconhece fatores externos que influenciam o ambiente interno: políticas econômicas, incertezas financeiras, disparidades em taxas de câmbio (real, dólar, euro, yen). O grupo reconhece uma forte instabilidade nas relações, pois fracas oscilações em taxas de câmbio geram fortes variações em operações locais. A resposta à questão alinhou-se quase que automaticamente à discussão anterior, encadeando o raciocínio do grupo.

\section{a região de excelência têm-se construtos de alta importância e alto desempenho que criam vantagem competitiva na indústria.}

A terceira questão investigou as características do cenário competitivo da operação. Alguns adjetivos surgiram na discussão: dinâmico, instantâneo, interligado, intrincado, caótico, oscilatório, sinérgico, complementar. Algumas expressões também surgiram: gestão do conhecimento; inteligência competitiva; gestão da informação; cadeias produtivas.

A terceira questão encerra a primeira parte da investigação e encaminha as duas questões seguintes, nas quais construiu-se a estrutura representativa dos fatores de competitividade da manufatura. Chegou-se a vinte e nove variáveis de avaliação.

A seguir formulou-se e aplicou-se ao grupo um questionário com uma escala de Likert de cinco categorias [péssima, ruim, média, boa e ótima] para as vinte e nove variáveis da estrutura de competição. Péssimo valeu um ponto, ótimo valeu cinco pontos, respostas intermediárias assumiram valores proporcionais. A pergunta foi:

- Considere que os fatores a seguir representam como a manufatura pode contribuir para a competitividade da nome da empresa - na indústria. Como você julga que está a situação atual de contribuição da manufatura em cada fator a seguir, relativo a si mesmo e aos concorrentes?

Após a aplicação do questionário, o grupo ponderou a estrutura pelo método AHP e avaliou a $C R$, a razão de consistência dos julgamentos, corrigindo de pronto as inconsistências identificadas. As CRs resultantes dos julgamentos corrigidos foram menores do que 0,10 , o que, segundo Saaty (1991), é aceitável. A estrutura em 
forma de árvore e a ponderação surgem na Tabela 1 e o modelo de desempenho competitivo na manufatura surge na Equação 1, na qual $a_{i}$ é a importância relativa e $C_{i}$ é o desempenho da $i$-ésima variável. Na Tabela 2 surgem os resultados individuais, as médias e coeficientes de variação e o resultado geral do questionário.

\section{DISCUSSÃO}

Da etapa qualitativa resultou uma estrutura em forma de árvore que representa os fatores de competição da manufatura. Algumas observações foram feitas nesta etapa:

Desempenho na manufatura $=\sum_{i=1}^{29} a_{i} \cdot C_{i} \quad$ Equação 1

Tabela 1: Estrutura de competitividade da manufatura.

\begin{tabular}{|c|c|c|c|}
\hline $\begin{array}{l}\text { TERMO } \\
\text { TEÓRICO }\end{array}$ & CONSTRUTOS & CONCEITOS & $\begin{array}{l}\text { IMPORTÂNGIA } \\
\text { RELATIVA } a,\end{array}$ \\
\hline \multirow{6}{*}{$\begin{array}{l}\text { competitividade } \\
\text { da manufatura } \\
\text { na indústria } \\
\text { (100\%) }\end{array}$} & $\begin{array}{l}\text { tecnologia } \\
33,91 \%\end{array}$ & $\begin{array}{l}\text { diversificação de produtos: } 9,15 \% \\
\text { conhecimento do requisito técnico do cliente: } 24,52 \% \\
\text { aderência a tendências tecnológicas universais claras: } 44,86 \% \\
\text { auto-suficiência tecnológica: } 15,63 \% \\
\text { metodologia de pesquisa em tecnologia: } 5,83 \%\end{array}$ & $\begin{array}{r}3,10 \% \\
8,32 \% \\
15,21 \% \\
5,30 \% \\
1,98 \%\end{array}$ \\
\hline & $\begin{array}{l}\text { qualidade } \\
25,29 \%\end{array}$ & $\begin{array}{l}\text { confiabilidade no desempenho do produto: } 16,55 \% \\
\text { confiabilidade de fornecedores: } 8,49 \% \\
\text { confiabilidade sistêmica no uso do produto: } 44,36 \% \\
\text { capabilidade no processo: } 25,97 \% \\
\text { agilidade no processo: } 4,64 \%\end{array}$ & $\begin{array}{r}4,19 \% \\
2,15 \% \\
11,22 \% \\
6,57 \% \\
1,17 \%\end{array}$ \\
\hline & $\begin{array}{l}\text { comunicação } \\
\text { com clientes } \\
20,04 \%\end{array}$ & $\begin{array}{l}\text { presença física pessoal junto ao cliente: } 33,33 \% \\
\text { informação que o pessoal de campo tem da manufatura: 33,33\% } \\
\text { informação que o pessoal de campo traz para a manufatura: 33,33\% }\end{array}$ & $\begin{array}{l}6,68 \% \\
6,68 \% \\
6,68 \%\end{array}$ \\
\hline & $\begin{array}{l}\text { serviço } \\
9,15 \%\end{array}$ & $\begin{array}{l}\text { assistência técnica ao longo da vida útil do equipamento: } 9,51 \% \\
\text { engenharia de solução segundo os processos do cliente: } 19,18 \% \\
\text { engenharia de solução segundo os produtos da manufatura: } 21,59 \% \\
\text { suporte técnico para o uso do produto pós-venda: } 43,25 \% \\
\text { treinamento: } 6,47 \%\end{array}$ & $\begin{array}{l}0,87 \% \\
1,75 \% \\
1,97 \% \\
3,96 \% \\
0,59 \%\end{array}$ \\
\hline & $\begin{array}{l}\text { entregas } \\
3,15 \%\end{array}$ & $\begin{array}{l}\text { presença física no território do cliente: } 7,67 \% \\
\text { capacidade de pronta entrega de produtos: } 14,12 \% \\
\text { sistema de informações via tecnologia da informação: } 4,66 \% \\
\text { conhecimento do produto e da aplicação pelo pessoal de campo: } 44,14 \% \\
\text { logística de distribuição: } 29,40 \%\end{array}$ & $\begin{array}{l}0,24 \% \\
0,44 \% \\
0,15 \% \\
1,39 \% \\
0,93 \%\end{array}$ \\
\hline & $\begin{array}{l}\text { custo } \\
8,45 \%\end{array}$ & $\begin{array}{l}\text { especificação da matéria-prima: } 29,67 \% \\
\text { logística de abastecimento e estocagem de matéria-prima: } 11,51 \% \\
\text { processo de cotação e aquisições: } 7,86 \% \\
\text { organização, alinhamento e governança na cadeia de valor: } 16,86 \% \\
\text { mão-de-obra: } 4,43 \% \\
\text { escala de produção e tamanho de lote: } 29,67 \%\end{array}$ & $\begin{array}{r}2,51 \% \\
0,97 \% \\
0,66 \% \\
1,43 \% \\
0,37 \% \\
2,51 \% \\
100 \%\end{array}$ \\
\hline
\end{tabular}


- o prévio conhecimento das questões parece ter facilitado a discussão, pois o grupo se preparou e organizou racionalmente seus argumentos;

- a visita prévia, a contextualização do problema e a tentativa de enquadramento na realidade da empresa parecem ter tranquiilizado e motivado os participantes quanto à utilidade das conclusões;

- o conhecimento empírico da indústria e a capacidade de argüição e articulação dos participantes parecem ter sido relevantes. Três critérios foram usados na seleção: forma- ção condizente, experiência empírica e trajetória reconhecida de sucesso na indústria; e

- os participantes trouxeram para o grupo focado a experiência da recente inserção de conceitos do BSC no planejamento estratégico, o que poderia ter enviesado a discussão. O enviesamento não ocorreu e o grupo separou e comparou dois objetos distintos.

$\mathrm{Na}$ etapa quantitativa avaliou-se multicriterialmente a estrutura, chegando-se a uma função-objetivo linear que

Tabela 2: Medição do desempenho competitivo da manufatura.

\begin{tabular}{|c|c|c|c|c|c|c|}
\hline \multirow[b]{2}{*}{ VARIÁVEL } & \multicolumn{4}{|c|}{ RESPONDENTES } & \multirow[b]{2}{*}{ MÉDIA $c_{1}$} & \multirow[b]{2}{*}{ GV } \\
\hline & R1 & Re & $\mathbf{R 3}$ & R4 & & \\
\hline diversificação de produtos & 3 & 3 & 4 & 3 & 3,25 & 0,15 \\
\hline conhecimento do requisito técnico do cliente & 4 & 4 & 5 & 4 & 4,25 & 0,12 \\
\hline aderência a tendências tecnológicas universais claras & 4 & 5 & 4 & 4 & 4,25 & 0,12 \\
\hline auto-suficiência tecnológica & 5 & 3 & 5 & 3 & 4 & 0,29 \\
\hline metodologia de pesquisa em tecnologia & 4 & 4 & 3 & 3 & 3,5 & 0,16 \\
\hline confiabilidade no desempenho do produto & 5 & 5 & 5 & 5 & 5 & 0,00 \\
\hline confiabilidade de fornecedores & 3 & 4 & 4 & 4 & 3,75 & 0,13 \\
\hline confiabilidade sistêmica no uso do produto & 5 & 4 & 5 & 5 & 4,75 & 0,11 \\
\hline capabilidade no processo & 4 & 4 & 4 & 5 & 4,25 & 0,12 \\
\hline agilidade no processo & 4 & 3 & 4 & 4 & 3,75 & 0,13 \\
\hline presença física pessoal junto ao cliente & 5 & 3 & 3 & 4 & 3,75 & 0,26 \\
\hline informação que o pessoal de campo tem da manufatura & 3 & 4 & 4 & 4 & 3,75 & 0,13 \\
\hline informação pessoal de campo traz para a manufatura & 4 & 4 & 4 & 3 & 3,75 & 0,13 \\
\hline assistência técnica ao longo da vida útil do equipamento & 5 & 5 & 4 & 4 & 4,5 & 0,13 \\
\hline engenharia de solução segundo os processos do cliente & 5 & 4 & 5 & 5 & 4,75 & 0,11 \\
\hline engenharia de solução segundo os produtos da manufatura & 5 & 4 & 5 & 5 & 4,75 & 0,11 \\
\hline suporte técnico para o uso do produto pós-venda & 4 & 5 & 5 & 4 & 4,5 & 0,13 \\
\hline treinamento de usuários & 4 & 5 & 5 & 4 & 4,5 & 0,13 \\
\hline presença física no território do cliente & 4 & 3 & 3 & 3 & 3,25 & 0,15 \\
\hline capacidade de pronta entrega de produtos & 3 & 5 & 4 & 4 & 4 & 0,20 \\
\hline sistema de informações via tecnologia da informação & 4 & 3 & 4 & 5 & 4 & 0,20 \\
\hline conhecimento do produto e da aplicação pessoal de campo & 5 & 5 & 5 & 4 & 4,75 & 0,11 \\
\hline logística de distribuição & 4 & 4 & 4 & 4 & 4 & 0,00 \\
\hline especificação da matéria-prima & 5 & 4 & 4 & 5 & 4,5 & 0,13 \\
\hline logística de abastecimento e estocagem de MP & 4 & 5 & 4 & 4 & 4,25 & 0,12 \\
\hline processo de cotação e aquisições & 3 & 4 & 5 & 4 & 4 & 0,20 \\
\hline organização, alinhamento e governança na cadeia de valor & 5 & 4 & 4 & 4 & 4,25 & 0,12 \\
\hline mão-de-obra & 5 & 4 & 4 & 5 & 4,5 & 0,13 \\
\hline escala de produção e tamanho de lote & 3 & 3 & 4 & 4 & 3,5 & 0,16 \\
\hline desempenho da manufatura \% & 80,53 & 77,12 & 82,61 & 77,86 & 79,53 & 0,03 \\
\hline
\end{tabular}


expressa a média das preferências estratégicas dos decisores. Estes avaliaram a manufatura por um questionário, segundo sua estrutura de preferências, chegando a uma conceituação média final para o estado do objeto em estudo.

Os decisores, ao tomarem conhecimento da ponderação, consideraram que a distribuição de importância relativa obtida descreveu sua percepção do cenário estratégico da operação. Ao tomarem conhecimento das suas avaliações e da avaliação média, consideraram que correspondem à sua percepção de momento. Os decisores também demonstraram satisfação com o formato apresentado e com as escalas usadas no questionário.

Pelo alpha de Crombach verificou-se a confiabilidade das respostas, adotando-se o limite de aprovação de Hair et al. (1998): 0,55. Consideraram-se (i) os respondentes como itens e as perguntas como casos; e (ii) as perguntas como itens e os respondentes como casos. Os resultados apresentados na Tabela 3 apontaram que os respondentes são confiáveis e que há ao menos três e possivelmente cinco perguntas a reformular.

As variáveis: (i) capacidade de pronta entrega de produtos; (ii) aderência a tendências tecnológicas universais claras; (iii) logística de abastecimento e estocagem de MP; (iv) assistência técnica ao longo da vida útil do equipamento; e (v) metodologia de pesquisa em tecnologia não foram suficientemente elucidadas antes do caso.

Uma hipótese a verificar é a troca da ordem de aplicação do método. É possível que, caso se tivesse aplicado o questionário após a discussão e a subseqüente ponderação, maior esclarecimento sobre os itens dúbios houvesse sido obtido, o que talvez tivesse contribuído para aumentar a confiabilidade do instrumento.

Outra verificação diz respeito à comparação dos resultados obtidos pelos conceitos com seu espaço para crescimento. Na Tabela 4 apresentam-se os valores atuais atribuídos aos conceitos, a distância à máxima pontuação possível e a ordem desta distância. Os conceitos de maior potencial de crescimento são: (i) a aderência a tendências tecnológicas universais claras; (ii) a informação que o pessoal de campo traz para a manufatura; (iii) a informação que o pessoal de campo tem da manufatura; e (iv) a presença física pessoal junto ao cliente. Chamam a atenção dois fatos: (i) a maior lacuna é apresentada pela variável de menor confiabilidade; e (ii) três variáveis com lacunas importantes pertencem ao mesmo construto, a comunicação com clientes. Quanto ao primeiro fato, talvez se devesse iniciar a recuperação da variável pelo esclarecimento e delimitação do que realmente se deseja melhorar. Quanto ao segundo fato, talvez as três variáveis possam ser tratadas por uma única ação.

Outra análise diz respeito à Figura 2. Nesta figura plotaram-se pares ordenados formados pela importância e pelo desempenho relativo dos construtos. O desempenho relativo é calculado dividindo-se a avaliação atual pela avaliação máxima que o construto pode alcançar. Os limites das regiões passam a um terço dos limites da figura. Entende-se que esta análise seja uma variante da análise apresentada em Slack (1993).

$\mathrm{Na}$ região de carência têm-se construtos de alta importância e baixo desempenho, que podem comprometer a competitividade da manufatura. Na região de excesso têm-se construtos de baixa importância e alto desempenho, que podem estar desperdiçando os recursos que faltam em outras posições. Na região de excelência têm-se construtos de alta importância e alto desempenho que criam vantagem competitiva na indústria. A região normal apresenta equilíbrio entre desempenho e importância.

Observa-se que a entrega e o serviço associado ao produto estão na região de excesso, enquanto que a tecnologia e a qualidade não estão na região de excelência. A tecnologia requer melhoria no desempenho, enquanto que a qualidade requer ações mercadológicas que aumentem sua importância na indústria. A criação destes construtos de alta importância e alto desempenho passa a ser um objetivo da manufatura, pois pode gerar uma vantagem competitiva na indústria. Uma reformulação estratégica seria o deslocamento de recursos empregados em entregas e em serviço para tecnologia e qualidade. Há viabilidade, haja vista que engenheiros de formação similar, recursos financeiros e equipamentos de teste são empregados tanto em entregas técnicas, instalação, trei-

Tabela 3: Verificação de confiabilidade do questionário.

\begin{tabular}{|c|c|c|c|c|}
\hline CASOS & ITENS & $\alpha$ DE CROMBACH & SITUAÇÃO & RETIRAR \\
\hline variáveis & respondentes & 0,59 & OK & - \\
\hline respondentes & variáveis & $-0,57$ & erro & variáveis 20, 3 e 25 \\
\hline & & 0,46 & erro & variáveis 14 e 5 \\
\hline & & 0,63 & OK & - \\
\hline
\end{tabular}

fonte: Elaborado pelos autores usando o sofware SPSS for Windows, v. 10.0.1, 1999. 
namento e assistência técnica, quanto em projeto, mercadologia e gestão da qualidade.

Custo e comunicação com clientes estão na região normal, o que é desejável, pois trata-se de fatores apriorísticos, e não exigem reformulações estratégicas.

\section{CONCLUSÃO}

O objetivo deste artigo era propor um método para a avaliação de desempenho de uma manufatura, baseado em critérios de competição, e apresentar uma aplicação do método proposto. Na base do método está o entendi- mento de que o desempenho é um termo teórico intangível, explicado por construtos e conceitos, que, ao serem avaliados, recuperam, explicam e mensuram, com uma dada confiabilidade, o termo teórico.

$\mathrm{O}$ método foi testado em uma manufatura de equipamentos eletrônicos, chegando-se a valores parciais e final de desempenho. Estes valores podem compor séries históricas e oferecer comparações dentro e fora da indústria. Entende-se que a estrutura construída é flexível, pois pesos, construtos e conceitos podem ser modificados sempre que as dimensões da competição se modifiquem. Como previsto, a metodologia exige em troca um

Tabela 4: Lacunas de desempenho.

\begin{tabular}{|c|c|c|c|c|}
\hline \multirow[b]{2}{*}{ VARIÁVEL } & \multicolumn{4}{|c|}{ RESPONDENTES } \\
\hline & MÁXIMA & ATUAL & LACUNA & ORDEM \\
\hline diversificação de produtos & $3,10 \%$ & $1,75 \%$ & $1,36 \%$ & 6 \\
\hline conhecimento do requisito técnico do cliente & 8,32\% & $6,76 \%$ & $1,56 \%$ & 5 \\
\hline aderência a tendências tecnológicas universais claras & $15,21 \%$ & $12,36 \%$ & $2,85 \%$ & 1 \\
\hline auto-suficiência tecnológica & $5,30 \%$ & $3,98 \%$ & $1,33 \%$ & 7 \\
\hline metodologia de pesquisa em tecnologia & $1,98 \%$ & $1,24 \%$ & $0,74 \%$ & 10 \\
\hline confiabilidade no desempenho do produto & $4,19 \%$ & $4,19 \%$ & $0,00 \%$ & 29 \\
\hline confiabilidade de fornecedores & $2,15 \%$ & $1,48 \%$ & $0,67 \%$ & 12 \\
\hline confiabilidade sistêmica no uso do produto & $11,22 \%$ & $10,52 \%$ & $0,70 \%$ & 11 \\
\hline capabilidade no processo & $6,57 \%$ & $5,34 \%$ & $1,23 \%$ & 8 \\
\hline agilidade no processo & $1,17 \%$ & $0,81 \%$ & $0,37 \%$ & 14 \\
\hline presença física pessoal junto ao cliente & $6,68 \%$ & $4,59 \%$ & $2,09 \%$ & 3 \\
\hline informação que o pessoal de campo tem da manufatura & $6,68 \%$ & $4,59 \%$ & $2,09 \%$ & 3 \\
\hline informação que o pessoal de campo traz para a manufatura & $6,68 \%$ & $4,59 \%$ & $2,09 \%$ & 2 \\
\hline assistência técnica ao longo da vida útil do equipamento & $0,87 \%$ & $0,76 \%$ & $0,11 \%$ & 23 \\
\hline engenharia de solução segundo os processos do cliente & $1,75 \%$ & $1,64 \%$ & $0,11 \%$ & 22 \\
\hline engenharia de solução segundo os produtos da manufatura & $1,97 \%$ & $1,85 \%$ & $0,12 \%$ & 20 \\
\hline suporte técnico para o uso do produto pós-venda & $3,96 \%$ & $3,46 \%$ & $0,49 \%$ & 13 \\
\hline treinamento & $0,59 \%$ & $0,52 \%$ & $0,07 \%$ & 26 \\
\hline presença física no território do cliente & $0,24 \%$ & $0,14 \%$ & $0,11 \%$ & 24 \\
\hline capacidade de pronta entrega de produtos & $0,44 \%$ & $0,33 \%$ & $0,11 \%$ & 21 \\
\hline sistema de informações via tecnologia da informação & $0,15 \%$ & $0,11 \%$ & $0,04 \%$ & 28 \\
\hline conhecimento do produto e da aplicação pelo pessoal de campo & $1,39 \%$ & $1,30 \%$ & $0,09 \%$ & 25 \\
\hline logística de distribuição & $0,93 \%$ & $0,69 \%$ & $0,23 \%$ & 17 \\
\hline especificação da matéria-prima & $2,51 \%$ & $2,20 \%$ & $0,31 \%$ & 15 \\
\hline logística de abastecimento, estoque e armazenagem de MP & $0,97 \%$ & $0,79 \%$ & $0,18 \%$ & 18 \\
\hline processo de cotação e aquisições & $0,66 \%$ & $0,50 \%$ & $0,17 \%$ & 19 \\
\hline organização, alinhamento e governança na cadeia de valor & $1,43 \%$ & $1,16 \%$ & $0,27 \%$ & 16 \\
\hline mão-de-obra & $0,37 \%$ & $0,33 \%$ & $0,05 \%$ & 27 \\
\hline escala de produção e tamanho de lote & $2,51 \%$ & $1,57 \%$ & $0,94 \%$ & 9 \\
\hline
\end{tabular}


Figura 2: Análise bidimensional de desempenho

desempenho \%

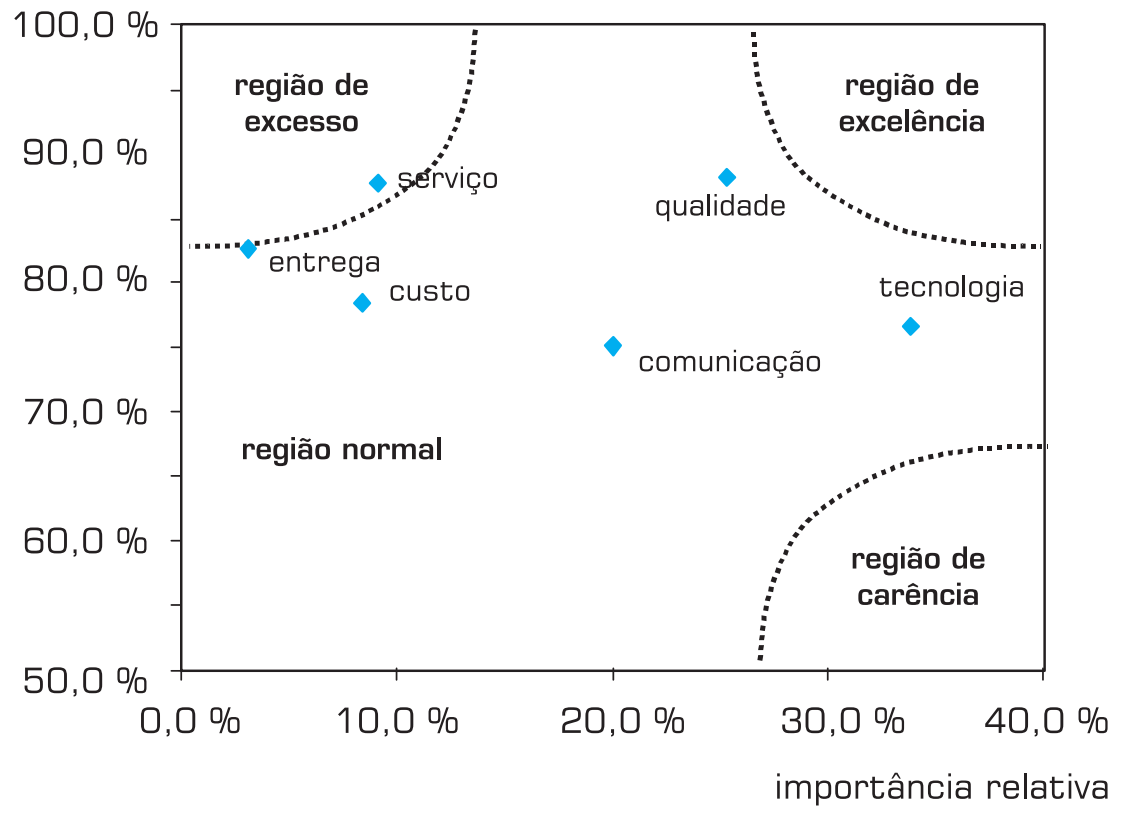

esforço na modificação: a cada atualização repete-se o procedimento de construção e ponderação da estrutura.

Ao adotar o AHP para a ponderação de construtos e conceitos, o método pressupôs independência mútua entre os critérios. Segundo Peteraf (1993), tal pressuposto nem sempre é válido. Remete-se para a continuidade sua relaxação, introduzindo mútuas influências na análise. Como o AHP assume uma inconsistência de até $10 \%$, também se remete à continuidade o uso de outros métodos multicriteriais de apoio à decisão.

A estrutura construída é incompleta, pois se limita a avaliações por meios indiretos, como o questionário. Para completar a medição, os conceitos devem ser desdobrados em indicadores de medição direta. Alguns destes indicadores são de imediata medição na manufatura, mas outros são de medição mais difícil. Esta dificuldade se relaciona tanto ao caráter da grandeza, que pode ser probabilística, como à sua definição, podendo haver discrepâncias de entendimento. Pode ser necessário incluir na definição da grandeza um modelo específico de medição. Remete-se para a continuidade das pesquisas o desdobramento do último nível da estrutura em indicadores de medição direta e nos respectivos modelos de medição. Este desdobramento requererá considerações acerca do sistema de informações da manufatura.

Finalmente considera-se que o objetivo do artigo era tratar da avaliação de desempenho em manufatura, mas, sendo esta um sistema de produção que pode se reorganizar, a avaliação ou medição de desempenho pode ser um passo em direção a ações de reformulação de estratégia. Esta reformulação já foi citada ao fim da discussão, em vista dos resultados da análise bidimensional. Entende-se, por fim, que o uso dos achados de pesquisa deste artigo podem ser usados na continuidade para a reformulação da atual estratégia. 


\section{- Referências Bibliográficas}

BOURNE, M.; MILLS, J.; WILCOX, M.; NEELY, A.; PLATTS, K. Designing, implementing and updating performance measurements systems. International Journal of Operations and Production Management, v. 20, n. 7 , p. 754-771, 2000

CARVALHO, M.; LAURINDO, F. Estratégias para competitividade. São Paulo: Futura, 2003.

CONTADOR, J. Modelo para aumentar a competitividade industrial. São Paulo: Edgard Blücher, 1996.

DAVIS, M.; AQUILANO, N.; CHASE, R. Fundamentos da Administração da Produção, Porto Alegre: Bookman, 2001.

EVANS, J. An exploratory study of performance measurement systems and relationships with performance results. Journal of Operations Management, n. 22, p. 219-232, 2004 .

FERRAZ, J; KUPFER, D.; HAGUENAUER, L. Made in Brazil: desafios competitivos para a indústria. Rio Janeiro: Campus, 1996.

GOMES, L.; ARAYA, M.; CARIGNANO, C. Tomada de decisão em cenários complexos. São Paulo: Thomson, 2004.

HAIR, J.; TATHAM, R.; ANDERSON, R.; BLACK, W. Multivariate data analysis. New Jersey: Prentice Hall, 1998.
HAYES, R.; WHEELWRIGTH, S. Restoring our competitive edge: competing through manufacturing. N. York: John Wiley \& Sons, 1984.

HILL, T. Manufacturing strategy: text and cases. London: Macmillian Business, 1995.

HRONEC, S. Vital signs: using quality, time, and cost performance measurements to chart your company's future. USA: Arthur Andersen Co.,1993.

HUDSON, M. SMART, A.; BOURNE, M. Theory and practice in SME performance measurement system. International Journal of Operations and Production Management, v. 21, n. 8, p. 1086-1115, 2001

KAPLAN, R.; NORTON, D. A estratégia em ação: o Balanced Scorecard. Rio de Janeiro: Campus, 1997.

KASUL, R.; MOTWANI, J. Performance measurements in world-class operations: a strategic model. Benchmarking for Quality Management \& Technology, v. 2, n. 2, p. 20-36 1995.

KENNERLY, M.; NEELY, A. Measuring performance in a changing business environment. Iternational Journal of operations and Production Management, v. 23, n. 2, p. 213-229, 2003.
MARTINS, R. Sistemas de medição de desempenho: um modelo para estruturação do uso. Tese de doutorado. Escola Politécnica. São Paulo: USP. 1999.

MIRANDA, L.; SILVA, J. Medição de desempenho. In: SCHMIDT, P (Org.). Controladoria: agregando valor para a empresa. Porto Alegre: Bookman, 2002.

MÜLLER, C. Modelo de gestão integrando planejamento estratégico, sistema de avaliação de desempenho e gerenciamento de processo. Tese de doutorado. PPGEP-UFRGS, Porto Alegre. 2003.

NEELY, A.; GREGORY, M.; PLATTS, K. Performance measurement system design: A literature review and research agenda. International Journal of Operations \& Production Management, v. 15, n. 4, p. 80-116, 1995.

PAIVA, E.; CARVALHO, L; FENSTERSEIFER, J. Estratégia de produção e de operações. Porto Alegre: Bookman, 2004

PETERAF, M. The cornerstones of competitive advantage: a resourcebased view. Strategic Management Journal, n. 14, p. 179-191, 1993.

PORTER, M. Estratégia competitiva: técnicas para análise de indústrias e da concorrência. Rio de Janeiro: Campus, 1998.
RIBEIRO, J.; NEWMANN, C. Planejamento e condução de grupos focados. In: RIBEIRO, J. (Org.) Grupos focados: teoria e aplicações. Porto Alegre: FEENG, 2003.

SAATY, T. Método de análise hierárquica, São Paulo: Makron, 1991.

SKINNER, W. Manufacturing - missing link in corporate strategy. Harvard Business Review, may-june, 1969.

SKINNER, W. Manufacturing strategy on the "S" curve. Production and operations management, v. 5 , n. 1 , p. 3-13, 1996.

SLACK, N. Vantagem competitiva em manufatura: atingindo competitividade nas operações industriais. São Paulo: Atlas, 1993.

SUWIGNJO, P; BITITCI, U.; CARRIE, A. Quantitative models for performance measurements system. International Journal of Production Economics, n. 64, p. 231-241, 2000.

TRACEY, M; VONDEREMBSE, M.; LIM, J. Manufacturing technology and strategy formulation: keys to enhancing competitiveness and improving performance. Journal of Operations Management, n. 17, p. 411-428, 1999.

WHEELWRIGTH, S. Manufacturing strategy: defining the missing link. Strategic Management Journal, v. 5, n. 1, p. 77-91, 1984.

WIENDAHL, H.-P. Load-oriented manufacturing control, Berlin Springer-Verlag, 1995.

\section{Reconhecimento}

Deseja-se reconhecer a contribuição dada a este artigo pelas discussões entabuladas com o professor PhD Jaime Evaldo Fensterseifer, do PPGA-UFRGS. Também se deseja reconhecer o papel exercido pelo professor PhD João Luiz Becker, pelo professor Dr. José Luiz Duarte Ribeiro e pelo professor Dr. Peter Bent Hansen, membros da banca que julgou a tese de origem deste artigo. Finalmente se agradece aos referees anônimos pela contribuição dada à forma final do artigo.

\section{- Sobre os autores}

\section{Miguel Afonso Sellitto}

Universidade do Vale do Rio dos Sinos - Unisinos

Professor do Programa de Pós-Graduação em Engenharia de Produção e Sistemas

Endereço: Av. Unisinos, 950 - 93022-000 - São Leopoldo - RS

Telefone: (51) 3591.1122

E-mail: sellitto@unisinos.br

\section{Cláudio Walter}

Universidade Federal do Rio Grande do Sul - UFRGS

Professor do Programa de Pós-Graduação em Engenharia de Produção

Praça Argentina, 9 - 90040-020 - Porto Alegre - RS

Telefone: (51) 3316-3491

E-mail: maxiprod@pro.via-rs.com.br 